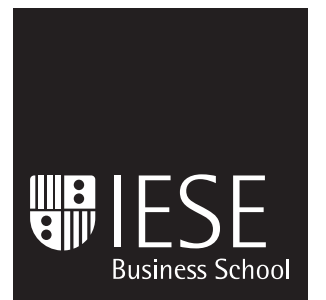

Working Paper

WP no 694

SP-SP

May, 2007

University of Navarra

\title{
TIME TO RETHINK MERGER POLICY?
}

\author{
Jordi Gual
}


The Public-Private Center is a Research Center based at IESE Business School. Its mission is to develop research that analyses the relationships between the private and public sectors primarily in the following areas: regulation and competition, innovation, regional economy and industrial politics and health economics.

Research results are disseminated through publications, conferences and colloquia. These activities are aimed to foster cooperation between the private sector and public administrations, as well as the exchange of ideas and initiatives.

The sponsors of the SP-SP Center are the following:

- Accenture

- Ajuntament de Barcelona

- Official Chamber of Commerce, Industry and Navigation of Barcelona

- BBVA

- Diputació de Barcelona

- Garrigues, Abogados y Asesores Tributarios

- Catalan Government (Generalitat de Catalunya)

- Sanofi-Aventis

- Telefonica

- T-Systems

- VidaCaixa

The contents of this publication reflect the conclusions and findings of the individual authors, and not the opinions of the Center's sponsors. 


\title{
TIME TO RETHINK MERGER POLICY?
}

\author{
Jordi Gual*
}

\section{Abstract}

This paper provides a critical analysis of some of the key features of merger policy as understood and practiced in leading jurisdictions such as the European Community and the United States. It focuses first on a discussion of the gradual move of merger policy towards the examination of unilateral effects. The critical appraisal of this process is based on the practical and theoretical shortcomings of the economic models that underlie the growing prominence of unilateral effects as the key anticompetitive factor arising from a proposed merger. The paper stresses that even if unilateral effects were to lead to an increase in the conventional measures of anticompetitive performance (such as markups), it is not clear that this would imply less competitive behavior for many of the most relevant industries in today's advanced economies. Finally, the paper also examines the relation between competition and welfare, and argues that even if competition does indeed diminish due to a merger, it is not a straightforward conclusion that this is not good in terms of economic welfare, when we take fully into consideration the incentives to innovate and the dynamic welfare gains that arise from new products and production processes.

* Professor, Economics, IESE and "la Caixa"

Classification J EL: L1, L4

Keywords: mergers, antitrust, competition policy

Forthcoming: Competition Policy International, Vol. 3, No. 1, Spring 2007. 


\section{TIME TO RETHINK MERGER POLICY?}

\section{Introduction}

This paper provides a critical analysis of some of the key features of merger policy as understood and practiced in leading jurisdictions such as the European Community and the United States. It focuses first on a discussion of the gradual move of merger policy towards the examination of unilateral effects. The critical appraisal of this process is based on the practical and theoretical shortcomings of the economic models that underlie the growing prominence of unilateral effects as the key anticompetitive factor arising from a proposed merger. The examination of why non-cooperative behavior is judged to be anticompetitive leads naturally to a discussion of the conceptual and empirical problems associated with the assessment of the level of competition in modern industries. Finally, the paper examines the last step in merger policy, the link between changes in competition levels and economic welfare, and argues that from a dynamic perspective it is not at all clear that less static competition leads to lower levels of welfare. This undermines the key relationship behind the well-known substantial lessening of competition test that has come to dominate merger policy practice.

This paper briefly reviews the trend towards the inclusion of unilateral effects analysis in merger policy, with a focus on recent changes in the European Community in Section 2. It then proceeds to an examination of the key shortcomings of this approach, Section 3, and of how the difficulties are compounded when the measure and welfare implications of both the level of competition and its rate of change are assessed, Sections 4 and 5 . Section 6 concludes with a few remarks on the implications of this analysis for the design and implementation of merger policy.

\section{Europe Follows the United States: The Adoption of a New Competition Standard for Mergers}

As recently highlighted by Vickers (2003a), competition policy is haunted by the meaning of words. The debate on the reform of the European Community (EC) merger regulation and its substantive competition test, provides a vivid example of this problem. Much of the controversy revolved around the scope of the dominance concept, and the extent to which it includes some post-merger oligopolistic situations where competition may be harmed, despite the absence of 
collusive intent, what has come to be known as unilateral effects. These situations, it was argued, are embraced by the alternative concept, the substantial lessening of competition (SLC) test.

For some observers, both tests had in practice led to substantially convergent outcomes, with broadly similar assessments of competitive situations on both sides of the Atlantic. Moreover, at the time of the EC merger reform, the European Court of J ustice had not yet ruled on potential damages to competition arising from non-cooperative behavior, and therefore the jurisprudence did not exclude that this possibility could be part of the conventional dominance concept. Nevertheless, those in favor of an adaptation of the test were able to convince the legislator of the need to move towards a broader framework, to ensure that no important cases were left out of the regulation.

At the end of the day, however, the final wording of the revised EC Merger Regulation ${ }^{1}$ is barely different from the old version, moving from preventing "a concentration which creates or strengthens a dominant position as a result of which effective competition... would be significantly impeded" to "a concentration which would significantly impede effective competition... in particular as a result of the creation or strengthening of a dominant position." The almost unchanged text reflects the need to provide continuity and consistency with the interpretation of the previous regulation provided by EC Court decisions, but it means that the intended extension of the concept was almost completely excluded from the articles of the regulation, and left for a detailed explanation in the recitals and the European Commission's Horizontal Merger Guidelines.

Recitals 24 to 26 of the regulation explicitly argue that: "under certain circumstances, concentrations involving the elimination of important competitive constraints that the merging parties had exerted upon each other, as well as a reduction of competitive pressure on the remaining competitors, may, even in the absence of a likelihood of coordination between the members of the oligopoly, result in a significant impediment to effective competition". ${ }^{2}$

The Merger Guidelines, in a section entitled "Non-Coordinated Effects", provide a detailed list of factors "that may influence whether significant non-coordinated effects are likely to result from a merger." ${ }^{3}$ Crucially, the list includes the degree of substitutability between the products of the merging firms, which is a key parameter if we wish to assess the presence of unilateral effects for a differentiated products market; and the availability of excess capacity to non-merging firms, this being the corresponding crucial aspect for the presence of unilateral effects in the homogeneous product case.

The final outcome of the debate reflected the views of influential academics and policy makers. For example, John Vickers (2003a) forcefully argued in favor of the SLC test, as did John Fingleton (2006), among others.

The 2003 Interim Report by Marc Ivaldi, Bruno Jullien, Patrick Rey, Paul Seabright, and Jean Tirole (hereinafter IDEI report) provides an attempt to justify technically the difference between dominance and a substantial lessening of competition. The authors argue that the dominance

\footnotetext{
${ }^{1}$ Council Regulation (EC) No. 139/2004 of J an. 20, 2004 on the control of concentrations between undertakings (the EC Merger Regulation), 2004 0.J . (L 24) 1 (J an. 29, 2004).

${ }^{2}$ Council Notice on Guidelines on the assessment of horizontal mergers under the Council Regulation on the control of concentrations between undertakings, 2004 0.J. (C 31) 5 (Feb. 5, 2004).

${ }^{3}$ Id. paragraphs 24 to 38 .
} 
test does not encompass all the range of anticompetitive outcomes. For example, using a standard Nash equilibrium concept for homogeneous goods competition, a merger of two firms in a five-firm industry with constant and equal marginal costs would lead to an increase in the markup of $5.25 \%$. Likewise, in a similar industry with three firms, one with a $60 \%$ market share and two equal firms each with a market share of $20 \%$, the merger of the smaller firms would raise prices by $6.75 \%$. This illustrates that the new short-run equilibrium involves higher prices achieved through unilateral effects. However, as the authors point out, the first example must involve some gains achieved through the reduction of fixed costs, and the second lead to a market structure that need not be less competitive in repeated interactions, since the new rival may well end up being a more viable competitor.

In conclusion, the revision of the EC Merger Regulation undertaken recently by the European Commission has led to an expansion in the range of anticompetitive effects that may be considered in EC merger cases, adding the unilateral effects that may arise as a result of noncooperative behavior. Some analysts think that this new approach will lead to excessive EC intervention. ${ }^{4}$ Others do not believe that this will be the case. ${ }^{5}$ In the following I intend to explore the issue further, by assessing the conceptual and practical robustness of unilateral effects analysis.

\section{The Popularity of Unilateral Effects}

The increasing use of unilateral effects arguments and models in merger cases is mostly due to their growing popularity among academic economists. Unilateral effects models appear to be grounded solidly in economic theory and, to a certain degree, offer a range of fairly consistent theoretical results. This is in sharp contrast with the alternative coordinated effects stories in which mergers are forbidden because of the potential increase in the likelihood of collusion among the remaining market players. The theory of collusion is perceived as less definitive, with a variety of possible equilibria, and the more or less informal establishment of lists of conditions that lead to potential anticompetitive behavior. Academic economists feel more at ease with the unilateral effects theory and, arguably, this is what has led to its dominance in the United States. ${ }^{6}$ This has, as in many other policy fields, been exported to the European Community.

Note, however, that Judge Posner, in the second edition of his well-known book on antitrust law, does not even mention unilateral effects. Nevertheless, the distinction between unilateral and coordinated effects already appears in a 1991 paper by Robert Willig in the run-up to the revised U.S. Horizontal Merger Guidelines. It has been fully articulated at the textbook level by Massimo Motta (2004), and inspired the new EC policy detailed in the IDEI report. The fourth edition of Kwoka and White's casebook (2003) also highlights the increased role of unilateral effects. However, the debate goes on. As recently as 2006, Dan Rubinfeld argued that unilateral effects theory is less conclusive than coordinated effects, is theoretically debatable, and has less case experience to build on.

\footnotetext{
${ }^{4}$ See, for instance, D. Ridyard (2005).

5 J. Vickers (2003b).

${ }^{6}$ See J.Baker (2003a, 2003b) .
} 
The examination of unilateral effects theory as a conceptual and practical basis for merger analysis should start from the key observation that merger policy - as opposed to other areas of antitrust - is not about assessing behavior based on observed facts. It is about anticipating behavior, and this means that the standard of proof - i.e., the degree of confidence that is required in order to make a finding - may have to be stronger than in other areas of competition policy. This fact has implications for both, the quality of the theory used and for the soundness of its empirical application. It also has consequences in terms of the design of the process by which mergers are approved (with or without conditions) or forbidden.

In the process of merger assessment, authorities may decide to minimize either type I errors (blocking efficient mergers) or type II errors (allowing anticompetitive mergers). If the key concern is to minimize type I errors, the process should be designed so that all mergers are allowed in principle, and specific deals are contested when the authorities can show, with a high degree of confidence, that the merger is anticompetitive.

If the goal is to minimize type II errors, the ideal approach would be to block all mergers in principle, and allow specific operations only if it could be shown convincingly (in this case by the parties involved) that these operations are procompetitive.

In principle, the procedure used by the European Community correctly focuses on minimizing type I errors, with the correct presumption that in a market economy companies will try to increase in size through mergers, and acquisitions, with the goal of improving their efficiency. Of course, the minimization of type I errors will crucially depend on how convincingly the potential anticompetitive effects have to be shown. Until recently, no efficiency considerations could be claimed, and this tended to increase the probability of blocking good mergers. Similarly, the standard of proof was not very high. Only recently the European Court of First Instance made it explicit that the anticompetitive effects have to be very likely (the phrasing used by the Court is that they have to occur "in all likelihood").

For our purposes, however, the key issue is whether unilateral effects theory, and its use in practice, provides a sound basis for the analysis of the presence of anticompetitive effects. In other words, with unilateral effects models, do we increase the probability of correctly assessing the existence and importance of the anticompetitive effects of a merger?

Of course, to the extent that we conclude - as discussed in the coming sections - that unilateral effects theory misleadingly categorizes as anticompetitive economic situations involving effective competition, it is clear that unilateral effects will increase the probability of type I errors. ${ }^{7}$

However, even if we were to accept unilateral effects theory, the key issue is whether its insufficient robustness, both in conceptual terms and in its practical application, will diminish our chances of correctly assessing prospective mergers. Is it possible with unilateral effects theory and practice to achieve a standard of proof as high as that required in merger analysis? Is it higher than the standard achieved with coordinated effects theory?

From the theoretical perspective, the economic model on which the authorities base decisions should be particularly robust. That is, it should be valid under alternative circumstances, even if analytical consistency and formal rigor diminish in importance. It is unclear whether this

\footnotetext{
${ }^{7}$ Fingleton (2006) argues, of course, exactly the opposite: that the exclusion of the unilateral effects from the dominance test increased the likelihood of type II errors, which to him should be of particular concern to authorities.
} 
requirement is satisfied by unilateral effects theory, and it may very well be better fulfilled by the old coordinated effects analysis. Even if it is hard to show formally that many mergers increase the likelihood of cooperative behavior, this is an intuitive result in a variety of wellknown scenarios, and there is not a lot of controversy about the set of observables that have to be present to make the case convincingly. On the contrary, in unilateral effects theory one can show with several simple comparative static exercises that unilateral effects may occur, but their generality and magnitude is uncertain, particularly when we assess competition in dynamic industries where the conventional oligopoly model is less well developed.

Indeed, it should be emphasized that the generality of the results, underpinning the theory behind unilateral effects, is unclear. As developed in the IDEI report and also by Werden and Froeb (2007), the results are basically tied to the static oligopoly model, exploiting the results that this model yields in terms of the relationships between firm-level and industry-level markups with measures of perceived elasticity of demand. The literature does analyze the implications in terms of entry and a more dynamic examination of the market, relationships such as those highlighted below in Section 5, but this is left as a complement, and the corresponding results are rather less conclusive than the ones that are key to the implementation of the unilateral effects approach.

The application of unilateral effects theory, based on formal oligopoly models, faces an additional hurdle. It does not fit adequately with the existing United States Merger Guidelines or its equivalent in the European Community. This is the case precisely because these Guidelines are the result of an indirect use of economic models as the background for merger analysis. In the present day, economic theory and its empirical application allow a more direct assessment of the parameters of interest, circumventing the Guidelines. On the other hand, however, the formal framework also has its shortcomings and, as argued before, it may be worthwhile retaining some of the flexibility of the proxy analysis used in the Guidelines.

It is certainly the case that market definition, for example, is a conceptual shortcut. It was designed years ago, as an intermediate step so that antitrust authorities could compute measures of market structure and its changes, and use them as a proxy of the changes in the degree of competition. The attempt to match the Guidelines with oligopoly theory is fraught with difficulties. The Guidelines focus the definition of the market on the assessment of own and cross-price elasticities, and leave the assessment of competitive reactions and entry for additional stages after the market has been defined. However, oligopoly theory highlights the need to be explicit about the reaction of rivals in determining the extent to which a would-be monopolist would be able to increase prices significantly for a certain amount of time. Thus, modern (static) oligopoly theory would assess the extent of the market by explicitly considering the competitive reaction of rivals, while the Guidelines leave that reaction for consideration after the market has been defined, in the context of competitive reactions and (non-sunk costs) entry. In fact, modern oligopoly theory, as highlighted repeatedly by authors such as Tim Bresnahan (2002) and Judge Posner (2001), makes the assessment of the size of the market irrelevant, to the extent that the increased possibility of raising prices after the merger is completely captured by the changes in the elasticity of the residual demand curves.

From an empirical point of view, the paper by Greg Werden, Luke Froeb, and David Scheffman (2004) provides a comprehensive analysis of the conditions that unilateral effects theory should 
satisfy for its use in merger analysis in practice. ${ }^{8}$ One of the key conditions is that it should be demonstrated that in the past, the theory used was applicable to the industry under examination and that, to be specifically used in a given case, it fits the facts to a reasonable degree.

This requirement is related to the broader discussion of how reliable the models developed by modern economic analysis are. Following a long tradition in modern economic methodology, these models are based on deductive introspective reasoning, rather than on asking the actors. Their assumptions need not be realistic, provided that they offer a parsimonious and reasonably accurate ex post explanation of the facts. Can this type of model be used reliably for the assessment of future situations? Will the estimated parameters remain stable after structural changes? Is the behavior of companies predictable and as hypothesized in the model? It seems to me that given the importance of the decisions that have to be taken, we should require not only that the model explains accurately the facts of the past, but also that it gives a good explanation for the behavior of companies after mergers of the past. This is crucial. As George Akerlof (2007) recently pointed out, modern economic theory has a built-in bias against alternative theories, with a very low power of statistical tests and a low probability of rejecting the null when false. Thus, "in almost every instance a large number of parsimonious models can be fitted statistically, making it hard - if not all but impossible - to statistically reject all variants of the model" ${ }^{9}$. One wonders whether this is a suitable framework to provide useful guidance for hypothetical scenario analysis such as the one needed in merger policy.

An example of the wealth of models available, and how easily they fit the data, is provided by the $\mathrm{MCl}$ Worldcom and Sprint merger, where the parties involved presented dramatically different empirical elasticity estimates using structural oligopoly models. ${ }^{10}$ As is well-known, the merger was abandoned due to the opposition of antitrust authorities, however, to a certain degree the events post-merger vindicate the arguments used by the companies in their defense of the deal. The focus of the discussion was the long distance market. The applicants argued that this was an industry in which margins were quickly collapsing, and which was in the midst of a structural change provoked by technological breakthroughs (the Internet) and regulatory changes (unbundling of local networks, etc.). The long distance market is a market in which the extent of product differentiation is limited, and in which the key competitive features are the high investment costs involved; the risk of competitive entry by new technologies (e-mail, chat through the Internet, webphones, etc.); powerful companies (the "Baby Bell", operating companies which could provide jointly long distance and local calling); and new competitive providers with brand new fiber. History has shown the importance of all these features. New entrants with new fiber have failed, but the new assets are there, the new services compete aggressively with traditional long distance, and local phone companies have indeed made substantial inroads into long distance by bundling their offers together with the supply of other services such as Internet access. Despite all of this, most of the disagreement focused on the alternative estimates obtained by the competing parties with regards to the extent of differentiation between the competitors involved. Whether $\mathrm{MCl} /$ Worldcom and Sprint were close substitutes or not, the question is certainly key to the extent to which a standard oligopoly model generates substantial price increases when simulating a merger, since the price

\footnotetext{
${ }^{8}$ See also D. Neven (2006).

${ }^{9}$ Akerlof (2007), page 46.

${ }^{10}$ For a description of the case, see Kwoka and White (2003), chapter 4. For a detailed discussion of the technical discrepancies between the two parties involved, see Werden and Froeb (2006). These authors review other cases (Volvo/Scania) involving substantial technical discrepancies between the parties.
} 
increases depend directly on the value of the estimated cross-price elasticity. However, it is not very clear that this is the appropriate framework to assess the competitive implications of the merger at a moment of structural change in the industry. Similarly, much of the discussion focused on the implied markups resulting from the estimated elasticities, thus neglecting the fact that this is an industry where scale economies are substantial and markups have to be assessed together with the fixed costs.

Ultimately, the choice of the economic models behind merger policy should be very careful, since there is already substantial debate on the efficacy of antitrust laws, and merger policy is a particularly sensitive area. It is very hard to evaluate ex post merger policies and there is considerable disagreement as to their effectiveness. ${ }^{11}$ This means that policy-makers should be especially careful in this area. Judge Posner says "it is hard enough to prove collusion; it is even harder to prove that a proposed merger will create a dangerous probability of future collusion", 12 and we may add that it is even harder to show that after the merger prices will unilaterally increase.

\section{What is the Appropriate Level of Competition?}

The assessment of mergers involves forecasting the competitive situation that will prevail after the merger. This is, as we have seen, a very complex exercise. Moreover, merger analysis also implies that this predicted level of competition (or lack of competition) should be assessed in terms of its impact on some measure of consumer or overall welfare.

It is important to emphasize, first of all, that when the anticompetitive effects of a merger on the existence of unilateral effects are predicated, the future post-merger scenario is one where non-coordinated or non-cooperative behavior prevails. This poses the question: To what extent should a non-cooperative equilibrium be considered uncompetitive? Many years ago, Friedrich Hayek (1948) already argued against this view. Quoting Dr. Johnson, he highlighted the etymological meaning of competition: "the action of endeavouring to gain what another endeavours to gain at the same time." From a modern game-theoretical perspective, such a definition fits quite well with what we today qualify as non-cooperative, profit-maximizing behavior. As Hayek already recognized, such behavior may lead - due to the structural characteristics of the market - to a markup of prices over marginal costs, but this need not imply that the market should be qualified as uncompetitive. Hayek focused at the time on product differentiation as the source of a positive competitive markup (the modern monopolistic competition model), and more recent analysis has developed new sources of competitive markups (contestable markets for the case of fixed costs that are not sunk and

\footnotetext{
${ }^{11}$ In 1999, the UK Office of Fair Trading (OFT) commissioned a study by National Economic Research Associates in which twelve cases of cleared mergers where examined. In the report, only two of the cases were found wrongly cleared and turned out to be anticompetitive. See National Economic Research Associates (1999). Apparently the authorities overestimated the power of buyers, the degree of substitutability, and the extent of technical change. See also Baker (2003a, 2003b) and R. Crandall and C. Winston (2003), pp. 15-20.

In addition, a paper by Tomaso Duso, Damien Neven, and Lars-Hendrik Roeller (2003) examines the effectiveness of EC policy to date. According to their work, in the period between 1990 and 2002 the Commission incurred in $23 \%$ of the cases type I errors, and in $28 \%$ of the cases type II errors.

${ }^{12}$ R. Posner (2001), page 119.
} 
sunk-costs competition otherwise, ${ }^{13}$ which make it difficult to assess the proper level of competition by a simple reference to relations between price and marginal cost.

The exact meaning of non-cooperative behavior and how it stands in relation to present or absent competition is exemplified by the discussion in the IDEI report. These authors distinguish carefully between unilateral effects, where there is "passive adaptation to market conditions," from tacit collusion where we find "anticipation of a response to one's own action," and behavior that "would not be in our own interest where it not for that anticipated reaction." ${ }^{14}$ It is at least questionable whether passive adaptation to market conditions should be viewed as non-competitive behavior.

What this implies is that, a priori, there is no reason to expect that non-cooperative behavior will lead to insufficient competition, and that, in practice, substantial effort should be devoted to analyzing the broad characteristics of the equilibrium (or business environment) post-merger, in order to carefully characterize and measure the extent of competition. Clearly, conventional analysis using structural measures such as market shares and concentration indices provides a very poor approximation to actual competitive conditions. However, as argued above, even a direct measurement of the price to marginal cost markup would be incorrect when the conditions of competition involve fixed costs (sunk or not). This, of course, extends also to the more sophisticated analysis of residual demand, which tries to assess directly, through econometric analysis, a measure of the extent to which other companies will restrain the pricing of the companies involved in the merger. Such an analysis is theoretically sound in the very limited number of markets where firms do not incur fixed costs, and is particularly inappropriate in markets where competition takes place through the escalation of fixed sunk costs. Indeed, in dynamic industries characterized by sunk-costs competition, or by network effects, the level of competition is incorrectly assessed by looking at price-cost markups. Firms gain competitive advantage by investing in advertising and research and development (R\&D), or by developing (direct and indirect) networks, and the excess pricing over marginal costs need not reflect economic inefficiencies, but rather the complex set of complementary services sold by these firms, and the need to obtain sufficient margins to pay for the fixed costs and ensure adequate profitability. ${ }^{15}$

In such a context, the discussion about the assessment of competition should focus on an analysis of the presence of (ex ante) excess profitability. In other words, profits in excess of the competitive rate of return, controlling for the risk involved in each type of activity. Profitability analysis is a controversial field in competition policy. It is true that accounting data on profits is plagued with difficulties. However, some authors argue that the problem is no greater than with other data typically used in antitrust proceedings, and this is an area that probably should be more prominent in antitrust analysis when industries with these characteristics are involved. ${ }^{16}$ Financial theory has developed good instruments for the measurement of excess returns. They involve the comparison of internal rates of return with the cost of capital adjusted for risk. In practice, the measurement of profitability must refer to short periods of time and requires the assessment of initial and terminal asset values, an exercise that - not surprisingly

\footnotetext{
${ }^{13}$ See J. Sutton (forthcoming 2007).

14 IDEI report, pages 3 and 4.

${ }^{15}$ On these issues, see, for instance, J. Gual (2004).

${ }^{16}$ See Oxera (2003).
} 
- turns out to be crucial for the proper evaluation of profitability in industries characterized by sunk-costs competition.

The assessment of what is an appropriate level of competition also has implications for market structure from a dynamic perspective. In industries with sunk costs or network effects, firms may anticipate further concentration, as companies try to sink more costs in order to improve their positioning in the marketplace, or exploit internally the positive externalities of networks. That is to say, the merger may have as an objective the achievement of a market position that is large enough to finance the increased sunk costs, and at the same time anticipate the competitive move of rival firms. There seems to be no clear reason why this type of deal should be considered anticompetitive.

A related argument has been made recently by Robin Mason and Helen Weeds (2006), albeit with a very stylized model. They argue that optimal merger policy should take into consideration that preventing some mergers (ex post) may lead to insufficient entry (ex ante). In their model, the entrant, given the uncertainty and the sunk costs it faces, will only enter if it can anticipate the merger as a potential way out, if profitability turns out to be insufficient. These authors consider that the effect they highlight is more general, and applies to any decision by a company that is difficult to reverse, has uncertain returns, and is affected by the possibility of a merger. ${ }^{17}$

From my perspective, the key point is that the merger may be a way to relax static competition, but need not imply a softening of dynamic competition. That is to say, at any point in time, the company may find that previous entry or investment decisions have not been correct and, therefore, that it is insufficiently profitable. Mergers are a way to restore profitability, but not necessarily above the competitive rate of return, given the risks involved in sunk costs competition.

The focus of competition policy should, therefore, move away from the comparative static analysis of the effects of changes in market structure (i.e., analysis of issues such as how markups change) towards a thorough examination which focuses on the dynamic features of industries. This means an analysis of the sustainability of the new market structure, and leads to an examination of the extent to which a merger significantly increases or decreases the barriers to entry into the industry.

On the issue of barriers to entry, it is well-known that in general they should be considered anticompetitive when they are artificial, but need not be considered so when they are the result of legitimate innovation and internal growth of a company, and do not involve the anticompetitive exclusion of rivals. These are the so-called strategic barriers to entry that form part of a dynamic competitive landscape.

Of course, a merger is not a case of internal growth and, from this perspective, the increase in strategic barriers is only legitimate to the extent that it is the result of an unavoidable change in market structure due to insufficient profitability. In this sense, it may be seen as an instance of the failing firm's defense that, within a proper analysis of profitability as mentioned above, could well be known as the insufficiently profitable firm defense.

\footnotetext{
${ }^{17}$ R. Mason and H. Weeds (2006), page 3.
} 


\section{Is Less Competition Always Bad?}

The final stage in merger analysis is the examination of the consequences of changes in the level of competition for some measure of aggregate welfare. In simple static models of oligopolistic competition, the relationship between the degree of competition and welfare is well known to be negative, but that need not necessarily be the case in dynamic settings, since the consequences for welfare are crucially dependent on the extent to which firms engage in product and/or process innovation. If the relationship between competition and the measure that assesses welfare is not linear, it cannot be taken for granted that a merger that substantially lessens competition will be detrimental to welfare.

A direct and simple link between competition and a dynamic assessment of welfare, as proxied by innovation, is well developed in the literature. For example, Damien Neven refers to the studies of Stephen Nickell and others, and concludes that competition matters for economic efficiency, and in particular for productive efficiency and in providing incentives to innovate. ${ }^{18}$ However, the economics profession is far from reaching a consensus in this area. Theoretical work by Xavier Vives (2004) provides arguments for a nonlinear relation between competition and measures of innovation activity, as does the work of Aghion and Griffith (2005), which also provides an empirical assessment of what they argue is an inverted U-shaped relationship. In fact, Aghion and Griffith start their argument by quoting Nickell (1996), where he disarmingly asserts that "the general belief in the efficacy of competition exists despite the fact that it is not supported either by any strong theoretical foundations or by a large corpus of hard empirical evidence in its favour." ${ }^{19}$

The positive impact of competition on the pace of innovation (the upward sloping part of the inverted U curve) corresponds to what Aghion and Griffith (2005) term the "escape the competition effect". From the perspective of the innovation race models that they use, it is a fairly general result that increasing the number of players (a measure of heightened competitive pressure) leads to renewed innovation efforts, as each player tries to stay ahead of their competitors in order to reap the benefits of success, escaping from the competition through the innovation race.

Vives (2004) obtains a similar effect using fairly general oligopoly models that are firmly based on the game-theoretical oligopoly model tradition, but nevertheless incorporate the dynamic efficiency gains that may be obtained through product and process innovation. In his work, again measuring the level of competition in relation to the presence of more competitors, the impact that more competition has on the R\&D effort is positive, to the extent that (in the presence of bankruptcy costs) a larger number of competitors diminishes expected profits, increases the chances of bankruptcy and, therefore, triggers a higher level of ex ante R\&D effort to improve efficiency.

At the same time, however, both approaches find that beyond a certain threshold, competition may in fact deter innovation and, as a consequence, thwart dynamic efficiency. In innovation race models, such as those encompassed by the general framework used by Aghion and Griffith (2005), are a Schumpeterian effect, whereby in certain contexts increased rivalry ex post (or the prospect of such a level of rivalry), diminishes incentives to innovate, because the possibility of appropriating innovation rents is diminished. Indeed, an antitrust policy that promotes

\footnotetext{
${ }^{18}$ Neven (2006), page 744, and S. Nickell (1996). For a review of empirical studies, see, for instance, S. Ahn (2001).

${ }^{19}$ Aghion and Griffith (2005), page 32.
} 
competition, but erroneously prevents large companies from developing legitimate commercial strategies may be relatively counterproductive in terms of its effect on R\&D and innovation.

The general class of oligopoly models discussed by Vives (2004) also generates a negative relation between increased competition and rates of innovation, to the extent that the presence of more competitors diminishes the demand faced by each firm and the expected rewards from innovation.

Overall, it is apparent that once we consider competition in a dynamic setting, taking into account the crucial effects of product and process innovation on welfare, the link between increased rivalry, understood as static competition, and welfare becomes less clear-cut than is commonly assumed. If we cannot simply conclude that less competition is bad, and if this lower level of competition comes about without collusion, explicit or tacit, then this implies, from a policy perspective, that the assessment of the consequences of mergers should remain at the level of examining their effects in terms of the variables that provide the more straightforward evaluation of the absence of competition. As argued before, these are the presence of excess profitability and the reinforcement of artificial barriers to entry.

\section{Concluding Remarks}

This essay has presented a broad critical analysis of what constitutes the mainstream approach to merger policy in western economies. The paper argues, first, that unilateral effects - the fashionable new approach behind merger policy - need not in fact imply anticompetitive behavior and, in any case, are very difficult to measure and use reliably in practice. Moreover, the paper stresses that even if these effects were to lead to an increase in the conventional measures of anticompetitive performance, such as markups, it is not clear that this implies less competitive behavior for many of the most relevant industries in today's advanced economies. Finally, the paper also examines the relation between competition and welfare, and argues that even if competition does indeed diminish due to a merger, it is not a straightforward conclusion that this is not good in terms of economic welfare, when we take fully into consideration the incentives to innovate and the dynamic welfare gains that arise from new products and production processes.

These three lines of criticism of current merger policy do not dispute the fundamental idea that economic analysis should be the basis for any proper examination of mergers. Rather, what they imply is that economic models are unavoidable abstractions of the real world that have to be handled with extreme care when used in important policy matters such as merger decisions. Despite the tremendous progress made by industrial organization theory over recent decades and the phenomenal improvement in quantitative methods, there remains a huge range of uncertainties regarding the appropriate model of competition for real-life industries, and merger policy should be deployed with a broad portfolio of analytical tools.

This is even more so because, as recently discussed by George Akerlof (2007), modern positive economics is biased, both theoretically and empirically, against models of behavior that, despite being potentially relevant in practice, incorporate non-objective arguments in utility functions and pay attention not only to what decision-makers do, but also to why they say they do it. This methodological bias excludes a non-trivial set of potentially powerful explanations of behavior, favoring abstract and parsimonious models over frameworks that may be less complete but are derived from the "knowledge of human nature and from the detailed facts of 
experience" ${ }^{20}$ and may be more insightful or appropriate. As a consequence, and given the complexity of real-life merger cases, it may be advisable to design merger policy in such a way that a broad range of economic analysis and evidence is collected, and the improvements in detailed techniques developed by economic theory and econometrics, should be carefully complemented by case-specific analysis, and a careful assessment of industry trends.

${ }^{20}$ A kerlof (2007), quoting J ohn Maynard Keynes. 


\section{References}

Aghion, P. and R. Griffith (2005), "Competition and Growth. Reconciling Theory and Evidence," The MIT Press.

Ahn, S. (2001), "Firm Dynamics and Productivity Growth: A Review of Micro Evidence from OECD Contries," OCDE, Economics Department Working Papers, No. 297, J une.

A kerlof, G.A. (2007), "The Missing Motivation in Macroeconomics," forthcoming in A merican Economic Review, working paper (Oct. 2005) available at:

http://www.econ.yale.edu/ shiller/behmacro/2005-11/akerlof.pdf.

Baker, J . (2003a), "Why did the Antitrust Agencies embrace unilateral effects?," 12 Geo. Mason L. Rev., pp. 31-37.

Baker, J. (2003b), "The Case for Antitrust Enforcement," J ournal of Economic Perspectives, No. 27, Fall.

Bresnahan, T. (2002), Comments on "Reforming European Merger Review: Targeting Problem Areas in Policy Outcomes," by Kai-Uwe Kühn, November, mimeo, Stanford University, available at:

http://www.stanford.edu/ tbres/research/Reforming\%20European\%20M erger\%20Review.pdf.

Crandall, R. W. and C. Winston, (2003), "Activist Antitrust?," J ournal of Economic Perspectives, Vol. 17, No. 4, Fall.

Duso, T., D. Neven, and L. Roeller (2003), "The Political Economy of European Merger Control: Evidence using Stock Market Data," WZB, Working Paper FS IV, pp. 2-34, available at: http://skylla.wz-berlin.de/pdf/2002/iv02-34.pdf.

Fingleton, J. (2006), "Does Collective Dominance Provide Suitable Housing for All Anticompetitive Oligopolistic Mergers?," in: B. Hawk (ed)., "International Antitrust Law \& Policy: Fordham Corporate Law," chap. 12.

Gual, J. (2004), "Market Definition in the Telecoms Industry," in: P. Buigues and P. Rey (eds.), "The Economics of Antitrust and Regulation in Telecommunications," Edward Elgar, Cheltenham.

Hayek, F.A. (1948). "The Meaning of Competition," in: "Individualism and Economic Order," The University of Chicago Press, Chicago.

Ivaldi, M. et al. (2003), IDEI Report, "The Economics of Unilateral Effects," Interim Report for DG Competition, European Commission, Institut d'Économie Industrielle, University of Toulouse, November, available at: http://idei.fr/doc/wp/2003/economics_unilaterals.pdf.

Kwoka, J.E. and L.J. White (2003), "The Antitrust Revolution: Economics, Competition and Policy," $4^{\text {th }}$ edition, Oxford University Press.

Mason, R. and H. Weeds (2006), "Merger Policy, Entry and Entrepreneurship," mimeo, University Essex, July, available at: http://privatewww.essex.ac.uk/ hfweeds/ffd19.pdf.

Motta, M. (2004), "Competition Policy: Theory and Practice," Cambridge University Press. 
National Economic Research Associates (1999), "Merger appraisal in oligopolistic markets," a report prepared for the U.K. Office of Fair Trading, Research Paper 19, November.

Neven, D. (2006), "Competition Economics and Antitrust in Europe," Economic Policy, No. 48, October.

Nickell, S. (1996), "Competition and Corporate Performance," Journal of Political Economy, No.104, pp. 724-746.

Oxera (2003), "Assessing profitability in competition policy analysis," a report prepared for the Office of Fair Trading, Economic Discussion Paper, No. 6.

Posner, R. (2001), "Antitrust Law," $2^{\text {nd }}$ Edition, The University of Chicago Press.

Ridyard, D. (2005), "The Commission's New Horizontal Guidelines: An Economic Commentary," Global Competition Law Centre, Working Paper 02/05, February.

Rubinfeld, D.L. (2006), "Antitrust Modernization Commission Hearings," Univ. Cal. Berkeley, Jan. 19, 2006, available at: http://www.amc.gov/commission_hearings/pdf/rubinfeld_statement_final.pdf.

Sutton, J. (2007), "Market Structure: Theory and Evidence," forthcoming in: "Handbook of Industrial Organization, Vol. III, M. Armstrong and R. Porter (eds.), North Holland.

Vickers, J. (2003a), "How to reform the EC merger test?," in: "EC Merger Control: A Major Reform in Progress," G. Drauz \& M. Reynolds (eds.), based on a speech given at the 2002 EC/IBA merger control conference, Brussels, Nov. 2002.

Vickers, J. (2003b), "How does the prohibition of abuse of dominance fit with the rest of competition policy?," in: "European Competition Law Annual," C.-D. Ehlermann and I. Atanasiu (eds. 2006), based on a speech given at the 8th Annual EU Competition Law and Policy Workshop at the European University Institute, Florence, J une.

Vives, X. (2006), "Innovation and competitive pressure," IESE, Working Paper No. 634, J une, available at: http://www.iese.edu/research/pdfs/DI-0634-E.pdf.

Werden, G.J . and L.M. Froeb (2006), "Unilateral Competitive Effects of Horizontal Mergers," forthcoming in: "Handbook of Antitrust Economics," P. Buccirossi (ed).

Werden, G.J., L.M. Froeb, and D.T. Scheffman (2004), "A Daubert Discipline for Merger Simulation," Antitrust Magazine, Summer.

Willig, R.D. (1991), "Merger Analysis, Industrial Organization Theory, and Merger Guidelines," Brookings Papers on Economic Activity. Microeconomics, Vol. 1991, pp. 281-332. 